\title{
Indian biotech centre rocked by controversy
}

\section{K. S. Jayaraman, New Delhi}

When the board of governors for the International Centre for Genetic Engineering and Biotechnology (ICGEB) meets next week, it may be in for a shock. The board, which represents the ICGEB's 43 member states, will find the centre's New Delhi component embroiled in controversy over allegations of insufficient funding, staff harassment and political influence on the recruitment of researchers and officials.

Set up 13 years ago by the United Nations Industrial Development Organization (UNIDO), the ICGEB was intended to spearhead the transfer of western biotechnology to developing nations. The centre is split into two components, one based in New Delhi, India, and the other in Trieste, Italy.

Earlier this year, officials at the New Delhi component denied reports that budget cuts and deteriorating working conditions had caused many scientists to leave (see Nature 403, 694 and 404, 329; 2000). But the complaints continue.

For example, the son of a senior official in India's Department of Biotechnology part of the Ministry of Science and Technology - has been appointed as an international fellow at the ICGEB. The move has raised a few eyebrows, as such positions are intended to be reserved for scientists from member countries other than India.

And Honey Reddi, a researcher in the virology department, claims she was "harassed" into resigning and then barred from entering the laboratory after she complained openly about working conditions and recruitment practices at the centre. She has now lodged formal complaints with India's National Commission for Women and its National Human Rights Commission.

There have also been accusations of lax management procedures. S. K. Panda, for example, a professor of pathology at the AllIndia Institute of Medical Sciences in New Delhi and a former consultant to the centre, holds a patent on the full-length clone of the

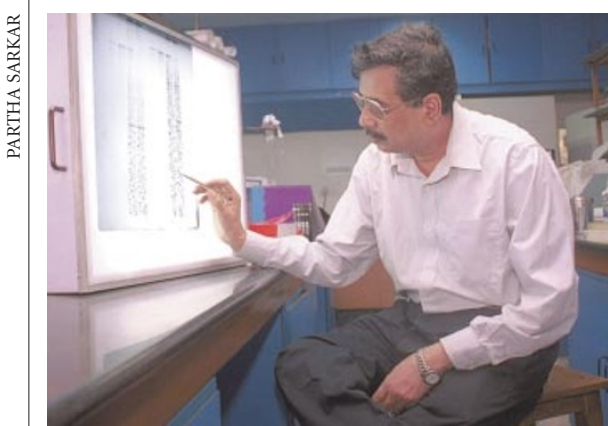

Panda: in dispute with the ICGEB over its handling of his clone of the hepatitis E genome.

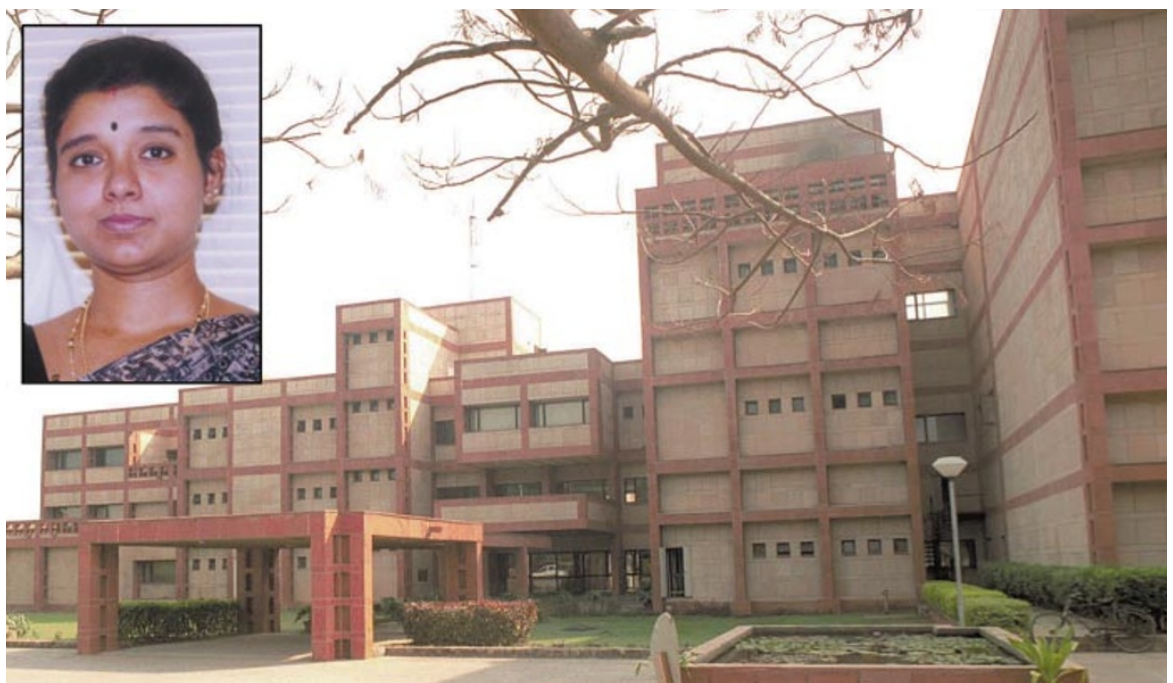

Barred? The ICGEB faces claims from Honey Reddi (inset) that she was "harassed" into resigning.

hepatitis $\mathrm{E}$ virus genome. He says that the ICGEB sent the clone to laboratories outside India without his knowledge, violating the material transfer agreement he had signed with the centre.

Although Panda's claim is currently under investigation, Arturo Falaschi, the Italian director of the ICGEB, dismisses the other complaints as "trivial". Virander Singh Chauhan, head of the Delhi component, describes allegations of political appointments as no more than "mischievous" propaganda.

Yashwantrai Vaishnav, who was a senior research scientist in the virology group until resigning in 1998, complains that "the politics is so deep-rooted at ICGEB that, it appears to me, no significant change can be brought about".

Vaishnav, who now works outside India after being one of 17 scientists to quit during the past two years, says that, although talented researchers remain, they are not being used properly because "the atmosphere at ICGEB is not conducive to it".

Chauhan denies there is anything wrong at the centre. "For the past two years, we have been continuously hiring people," he says. "Most of the people who left were here either on project positions or on short-term fellowships."

Responding to charges that the appointments process lacks transparency, Chauhan says: "On the contrary, I think we are too open ... not even a technician is recruited without advertising for the post and a selection committee."

But Devaguptapu Subrahmanyam, who was closely associated with the development of the ICGEB as a UNIDO official and later as a senior adviser at the New Delhi component, argues that the centre's recruitment procedures "need to be revamped". In partic- ular, he says, all senior positions "should be filled by advertisement through international media".

"There are clearly some serious problems with this unit, and an external review is needed to get to the bottom of it," says Deshpal Verma, professor of molecular genetics at Ohio State University. Verma was first choice to head the New Delhi unit when it was set it up by UNIDO in 1987, but rejected the offer.

Like Chauhan, several members of the ICGEB's Council of Scientific Advisors (CSA) reject criticism of its operation. "The scientific contributions of the Trieste and New Delhi laboratories are world class, and the training and help given the centre's member states are of extraordinary value," says one, Nobel laureate Arthur Kornberg of Stanford University School of Medicine.

Another CSA member, Govindarajan Padmanaban of the Indian Institute of Science in Bangalore, says he is not aware of internal problems at the centre. "My overall impression of ICGEB is positive," he says.

Contributing to the current tension is concern over future funding prospects for the centre. According to Subrahmanyam, its long-term financial stability "looks uncertain", as a number of member countries are behind with their dues, and the two host countries - India and Italy — are both showing signs of "donor fatigue".

Subrahmanyam argues that it is now vital for the ICGEB to persuade other developed countries to become members. But this will mean giving the centre a stronger international profile. At present, he points out, hardly any of the senior positions in the New Delhi component are held by non-Indians.

http://www.icgeb.trieste.it 